\title{
Dementia and Communication Pathology: Two Case Examples
}

\author{
Claire Penn, Ph.D. (Witwatersrand) \\ Beulah Sonnenberg, (Speech and Hearing Therapy) (Witwatersrand) \\ Yael Schnaier, (Speech and Hearing Therapy) (Witwatersrand) \\ Department of Speech Pathology and Audiology \\ University of the Witwatersrand, Johannesburg
}

\begin{abstract}
The discourse characteristics of two female patients with dementia are described - one patient with a cortical dementia of Alzheimer's type and one patient with a classical subcortical dementia of Progressive Supranuclear Palsy. Distinct patterns of breakdown were observed and related to an explanatory model. Implications of the findings for differential diagnosis are discussed and the neurological representation of the pragmatic level of language is considered.
\end{abstract}

\section{OPSOMMING}

Die gesprekvoeringseienskappe van twee vroulike pasiënte met demensie word beskryf. Een pasiënt ly aan 'n kortikale demensie van die Alzheimer tipe en die ander een aan 'n kenmerkende demensie, nl. Progressiewe Supranukleêre Verlamming. Bepaalde simptoomgroepe is waargeneem en in verband gebring met 'n verduidelikende model. Die implikasies van die resultate ten opsigte van 'n differensiaal-diagnose word bespreek en die neurologiese verteenwoordiging van die pragmatiese taalvlak word oorweeg.

\section{INTRODUCTION}

The role of the language pathologist in the area of dementia has been increasingly acknowledged during the past few years particularly in the field of differential diagnosis. Language and communication testing thus forms an important part of the diagnostic battery for dementia. Dementia may be broadly defined as a "condition of chronic progressive deterioration of intellect, memory, personality and communicative function resulting from organic brain disease" (Bayles 1984).

Various types of dementia have been identified. Among the most common classification schemes is the subdivision of dementia into cortical and subcortical types depending on the anatomic site of lesion (Albert 1978; Cummings \& Benson 1984). This classification has been a division of some controversy and will be the focus of the present paper. Essentially cortical dementia refers to the cluster of symptoms arising from damage to cortical areas and resulting in symptoms such as apraxia, memory impairment and aphasia (Cummings \& Benson 1984). As such, this type of dementia is traditionally measured by standard cortical, neuropsychological and language tests.

The most classic example of a cortical dementia is Dementia of Alzheimer's type (DAT) which is characterized by cortical atrophy particularly in the frontal, parietal and temporal lobes as well as ventricular dilatation. Microscopically the presence of neuritic plaques, neurofibrillary tangles and areas of granulovacuolar degeneration in the temporal lobe and hippocampus are indicative of DAT (Schneck, Reisberg \& Ferris 1982). Resulting symptoms as formally specified in DSM III of the American Psychiatric Association (1980) include intellectual dysfunctions sufficient to interfere with social behaviour, memory impairment and at least one of the following: personality change, impairment in abstract thinking, poor judgment and aphasia, apraxia or agnosia.

Subcortical dementia results form involvement of the thalamus, basal ganglia and the rostral brain stem nuclei (Albert, Feldman \& Willis 1974; Cummings \& Benson 1984) with relative sparing of the cerebral cortex. The pattern of dementia involves a slowness of mental processing, forgetfulness, impaired cognition, apathy and depression and an impaired ability to manipulate acquired knowledge. Language symptoms have been documented as being mild or indistinct (Obler \& Albert 1981; Cummings \& Benson 1984). Traditional neuropsychological measures are less sensitive to subcortical dysfunction. Cited examples of subcortical dementias include Parkinson's disease, Huntington's disease and Progressive Supranuclear Palsy (PSP). The latter condition is considered to be the best example of a subcortical degenerative process in which dementia is a consistent finding (Kristensen 1985; Cummings 1986). This disease entity is characterized by supranuclear opthalmoplegia, pseudobulbar palsy, axial rigidity and dystonia, dysarthria, dysphagia and a mild, slow progressive dementia (Albert 1974; Kirstensen 1985;Maher \& Lees 1986|.

Anatomically the lesion in PSP is fairly widespread and involves neuronal loss, granulovacuolar degeneration, gliosis and neurofibrillary tangles (Jonati \& Appell 1984). Cortical hypometabolism is also evident in PSP through the loss of subcortical afferents to the prefrontal cortex AAlbert 1987; D'Antona, Baron, Samson, Serdara, Vidder, Agid \& Cambier 1985; Huber \& Paulson 1985; Cummings 1986; Maher \& Lees 1986).

While certain writers (eg. Bayles 1984) argue that the divi- 
sion of dementias into cortical and subcortical appears "perplexing and premature", because of the overlap of symptoms and the anatomical connection between cortical and subcortical areas, (Mayeux, Stern, Rosen \& Benson 1983; Maher, Smith \& Lees 1985; Pillon, Dubois, Lhermitte \& Agid 1986) recent writers continue to explore the possibility of discrete clinical profiles (Freedman 1984; Cummings 1986; Huber, Shuttleworth, Paulson, Bellchambers \& Clapp 1986|.

Table I illustrates the similarities and differences between the two types of dementia investigated in the present study and highlights the basis of this debate.

Cummings $[1986\}$ in an excellent review article on subcortical dementia, suggests that cortical and subcortical abilities can be categorized as instrumental and fundamental functions respectively. Instrumental functions are the most highly developed of human abilities and depend on phylogenetically recent and ontogenetically late developing structures. Instrumental abilities include language praxis, perceptual recognition, memory and calculation and depend on the integrity of discrete cortical regions. Abnormalities of these functions produce deficits associated with cortical dementias including aphasia, apraxia, agnosia, amnesia and acalculia.

Fundamental functions are essential for survival and emerge early in ontogenetic and phylogenetic development. These functions which include arousal, activation, attention, sequencing, motivation and mood are less discretely neurologically organized and involve subcortical structures (basal ganglia and thalamus) that interconnect widely with the cerebral cortex. Abnormalities of fundamental functions produce the cardinal features of subcortical dementia including deficits in information processing, mood, cognition and motivation.

Inter-etiologic comparison of subcortical and cortical dementia allows one to observe the effect of such fundamental functions versus instrumental functions on communication skills. Bayles and Kaszniak (1987) feel that further inter-etiologic comparison is needed especially within the realm of language and communication. This becomes particularly important when considering possible differential treatment options. Systematic attempts to describe language disturbance in dementias have been rare and results are often contradictory, probably because the traditional aphasia measures which have been utilized are insensitive to pertinent discourse features of dementia (Appell, Kertesz \& Fishman 1982). Other aspects studied include: confrontation naming, receptive vocabulary, word association, reading comprehension, sentence judgment and correction, pantomime recognition, and verbal fluency (Bayles \& Kaszniak 1987).

Such studies, most often conducted on parties with cortical dementias, generally conclude that while syntactic and phonologic levels of language remain relatively unaffected particularly in early stages, the semantic and pragmatic levels of language are most often affected. This has been particularly noticeable in the studies undertaken on discourse dimensions leg. Bayles \& Tomoeda 1983; Horner \& Royall, 1985). Discourse is a particularly sensitive indicator of social and cognitive competence and seems to be implicated in all types and phases of dementia. Little research on the discourse level exists particularly in subcortical dementia.

\section{CLINICAL INVESTIGATION}

\section{Patients}

Two female patients with dementia of moderate severity were used in the study:

\section{Patient with DAT (Patient A)}

A was seen at the University Speech and Hearing Clinic at the age of 56 years. She first noticed difficulties in certain cognitive functions three years previously. She reported a lack of concentration, memory and a degree of disorientation. She had a series of neurological and neuropsychological assessments both locally and overseas which revealed generalized brain atrophy with no significant focal abnormalities, but large ventricles with enlargement of the sulci. There was no evidence of endocrine or metabolic disease. The condition was diagnosed as presenile dementia of the Alzheimer's type. No family history of any neurological disease was reported and there was no history of alcohol or drug abuse. Premorbidly, A was an intelligent lively person, educated at a tertiary level and running her own business.

Initial diagnostic testing on an aphasia battery revealed a mild slurring pattern of articulation especially on more complex words or words containing blends or fricatives; on receptive language tasks she showed difficulties with complex material; severe word finding difficulties in expressive language affecting flow, severe dyslexia, dysgraphia and acalculia. Self-correction behaviour was evident during test performance. Details of the neuropsychological assessment are not available, but the neurological report revealed a typical pattern of memory, visuospatial and cognitive deficits.

\section{Patient with PSP (Patient B)}

B was 64 years old when referred for a speech and language assessment. Her disease onset was six years previously and presented with slight personality changes, frequent falls, and reduction in rate and volume of speech. At this time, Alzheimer's disease was posited, but four years later afte'r further deterioration in physical, psychological and speech status, together with dysphagia, PSP was diagnosed. A' medical examination revealed marked akinesia of trunkal movements, axial rigidity and dystonia in extension. Supra; nuclear opthalmoplegia, palsy of vertical eye movement and restricted lateral gaze were present. Facial features were stiff and immobile with lack of facial expression. These features are in accordance with characteristics of PSP as described by a number of authors, (Jonati \& Appell 1984; Kristensen 1985, Izzo, Dilotenzo \& Roth 1986). CAT scans with contrast revealed a moderate widening of the cortico. subarachnoid channels, specifically in the posterior fossa, together with some atrophy in cortical and cerebellar areas. Compression of the lateral ventricles and dilation of the quadrigeminal cistern were present. This is in accordance with findings by Ruberg et al. (1985). Extensive neuropsychological testing showed a mild level of dementia, involving an early intellectual concretism, impaired concentration, intact immediate memory and an impairment of recent 
Table I: Contrasting features of cortical (DAT) and Subcortical (PSP) dementias

AFTER Albert et al. (1974); Appel et al. (1982); Bayles \& Kaszniak [1987); Cummings (1986); Cummings \& Benson (1984); Cummings \& Benson 1986); Huber \& Paulson (1985); Obler \& Albert (1981); Schneck et al. (1982); Steele, (1972).

\begin{tabular}{|c|c|c|}
\hline Characteristics & Cortical Dementia (DAT) & Subcortical Dementia (PSP) \\
\hline $\begin{array}{l}\text { Initial } \\
\text { symptomatology }\end{array}$ & $\begin{array}{l}\text { - memory impairment } \\
\text { - personality/mood changes } \\
\text { - intellectual dysfunction } \\
\text { - gait normal } \\
\text { - no dysarthria }\end{array}$ & $\begin{array}{l}\text { - progressive impairment of memory } \\
\text { - personality changes } \\
\text { - slowing of mental operations } \\
\text { - disturbances of gait } \\
\text { - postural instability } \\
\text { - altered vision } \\
\text { - dysarthria } \\
\text { - dysphagia }\end{array}$ \\
\hline $\begin{array}{l}\text { Progression of } \\
\text { disorder }\end{array}$ & $\begin{array}{l}\text { - progress more rapidly than subcortical forms } \\
\text { - as cortical degeneration progresses, loss of } \\
\text { higher order associative functions }\end{array}$ & $\begin{array}{l}\text { - steady progressive deterioration of all signs } \\
\text { and symptoms }\end{array}$ \\
\hline Neuropathology & $\begin{array}{l}\text { Macroscopically } \\
\text { - cortical atrophy in parietal, temporal, frontal } \\
\text { lobes } \\
\text { - ventricular dilation of mild-moderate degree } \\
\text { - cerebral cortex involved } \\
\text { - basal ganglia, thalamus, mesencephalon } \\
\text { largely spared } \\
\text { Microscopically } \\
-\quad \text { senile or neuritic plaques, neurofibrillary } \\
\text { tangles } \\
\text { - granulovacuolar degeneration in temporal } \\
\text { lobe and hippocampus }\end{array}$ & $\begin{array}{l}\text { Macroscopically } \\
-\quad \text { fairly widespread lesion throughout sub- } \\
\text { cortex involving basal ganglia, thalamus and } \\
\text { structures } \\
- \text { cerebral cortex largely spared } \\
- \text { frontal lobe involvement via subcortical pro- } \\
\text { jections to prefrontal cortex } \\
\text { Microscopically } \\
- \text { neuronal loss, granulovacuolar degeneration } \\
- \text { gliosis, neurofibrillary tangles }\end{array}$ \\
\hline $\begin{array}{l}\text { Neuropsychological } \\
\text { features }\end{array}$ & $\begin{array}{l}\text { - more severe deficits earlier in disease course } \\
\text { - progressive dementia with aphasia, amnesia } \\
\text { and early cognitive impairment } \\
\text { - normal speed of cognition } \\
\text { - memory disturbed early in the course } \\
\text { - impaired visuospatial skills }\end{array}$ & $\begin{array}{l}\text { - Mild to moderate deficits throughout most of } \\
\text { course } \\
\text { - mild, slow, progressive dementia with poor } \\
\text { abstraction and categorization } \\
\text { - slowed speed of cognition and response } \\
\text { latency } \\
\text { - memory disturbances are a cardinal feature } \\
\text { - impaired visuospatial skills }\end{array}$ \\
\hline Neuropsychiatric & $\begin{array}{l}\text { - indifferent; unconcerned } \\
\vdots \\
\text { - depression uncommon } \\
\text { - absent mania }\end{array}$ & $\begin{array}{l}\text { - marked personality changes: apathy; irritabi- } \\
\text { lity; brief outbursts of rage } \\
\text { - depression common } \\
\text { - infrequent mania }\end{array}$ \\
\hline Physical features & $\begin{array}{l}\text { - normal psychomotor speed } \\
\text { - motor functions normal until final stages of } \\
\text { DAT } \\
\text { - normal posture and co-ordination } \\
\text { - normal gait } \\
\end{array}$ & $\begin{array}{l}\text { - axial rigidity and dystonia } \\
\text { - slow, broad-based giat } \\
\text { - } \text { supranuclear opthalmoplegia }\end{array}$ \\
\hline $\begin{array}{l}\text { Speech and } \\
\text { language features }\end{array}$ & $\begin{array}{l}\text { - aphasia (transcortical sensory; Wernickes]; } \\
\text { agnosia and apraxia } \\
\text { - no dysarthria } \\
\text { - } \text { syntax relatively spared } \\
\text { - most prominent early defect is marked } \\
\text { semantic loss (verbal paraphasias] } \\
\text { - phonology preserved } \\
\text { - normal, fluent speech output } \\
\text { - personalized, irrelevant and repetitious } \\
\text { speech with frequent circumlocutions and } \\
\text { semantic jargon } \\
\text { - anomia - benefits little from clues } \\
\text { - comprehension skills more impaired parti- } \\
\text { cularly of more complex material } \\
\text { - ibreakdown of language as a tool for commu- } \\
\text { nicating with others }\end{array}$ & $\begin{array}{l}\text { - no aphasia; agnosia; apraxia } \\
\text { - dysarthria } \\
\text { - syntax intact } \\
\text { - semantic paraphasias } \\
\text { - altered speech output - little spontaneous } \\
\text { - speech; fragmented sentences; dysfluencies } \\
\text { - normal or mild anomia - profit from clues } \\
\text { - frontal lobe signs, eg. abnormal verbal fluency } \\
\text { - intact receptive language or mild deficit }\end{array}$ \\
\hline
\end{tabular}


verbal and nonverbal memory. Certain features of a cortical dementia were also present via involvement of the frontal lobe. This was evident in signs of perseveration, reduced word fluency and the dissociation between thought and action.

On an aphasia battery she revealed unintelligible speech due to a severe dysarthria. Receptive language was primarily intact. She used telegrammatic expressive language with limited use of complex sentences. Perseveration of words and phrases was evident. There was a breakdown in word fluency, flexibility and speed of word retrieval. Very little awareness of test performance scemed evident (no selfmonitoring). Severe dysgraphia was present.

Details of subject characteristics and performance on standard tasks are presented in table II.

Table II: Subject characteristics and performance on standardized tasks

\begin{tabular}{|c|c|c|}
\hline Characteristics & Subject A (DAT) & Subject B $\{\mathrm{PSP}\}$ \\
\hline$\underline{\text { Sex }}$ & Female & Female \\
\hline $\begin{array}{l}\text { Age at onset and at } \\
\text { time of testing }\end{array}$ & $52(1981)$ and $55(1984)$ & $58\{1981)$ and 65 (1987\} \\
\hline Final diagnosis & $1984-\mathrm{DAT}$ & $1985-$ PSP \\
\hline Educational level & Tertiary education & Tertiary education \\
\hline $\begin{array}{l}\text { Environmental } \\
\text { support } \\
\end{array}$ & $\begin{array}{l}\text { Strong family support from husband, sister, } \\
\text { friends }\end{array}$ & Strong support from husband, friends \\
\hline $\begin{array}{l}\text { Initial } \\
\text { symptomatology }\end{array}$ & $\begin{array}{l}\text { - difficulties in certain cognitive functions } \\
- \text { lack of concentration, memory } \\
\text { - degree of disorientation } \\
- \text { dysgraphia } \\
- \text { slurring specch - difficulty with polysyllabic } \\
\text { words }\end{array}$ & $\begin{array}{l}\text { - slight personality changes } \\
\text { - frequent falls } \\
\text { - reduction in rate and volume of speech }\end{array}$ \\
\hline $\begin{array}{l}\text { Neurological } \\
\text { involvement }\end{array}$ & $\begin{array}{l}\text { degree of generalized cerebral atrophy with } \\
\text { slight dilation of lateral ventricles and en- } \\
\text { largement of sulci }\end{array}$ & $\begin{array}{l}\text { - moderate widening of cortico-subarachnoid } \\
\text { channels, specifically in posterior fossa } \\
\text { - general atrophy in cortical and cerebellar } \\
\text { areas } \\
\text { - compression of lateral ventricles and dilation } \\
\text { of quadrigeminal cistern }\end{array}$ \\
\hline $\begin{array}{l}\text { Neuropsychological } \\
\text { features }\end{array}$ & $\begin{array}{l}\text { moderate generalised cerebral dysfunction } \\
\text { involving all cognitive, perceptual and moto- } \\
\text { ric abilities - compatible with dementia }\end{array}$ & $\begin{array}{l}\text { - mild dementia } \\
\text { - early intellectual concretism } \\
\text { - impaired concentration } \\
\text { - intact immediate memory } \\
\text { - impaired recent verbal and non-verbal } \\
\quad \text { memory }\end{array}$ \\
\hline $\begin{array}{l}\text { Neuropsychiatric } \\
\text { features }\end{array}$ & $\begin{array}{l}\text { - buoyant, cheerful, friendly personality } \\
\text { - alert } \\
\text { - high level of awareness }\end{array}$ & $\begin{array}{l}\text { - depressed } \\
\text { - apathetic }\end{array}$ \\
\hline Physical features & $\begin{array}{l}\text { - youthful appearance } \\
\text { - exercises daily with good co-ordination, } \\
\text { normal gait and station }\end{array}$ & $\begin{array}{l}\text { - marked akinesia of trunkal movements } \\
\text { - axial rigidity } \\
- \text { dystonia in extension } \\
- \text { gait }- \text { small steps with tendency towards } \\
\text { retropulsion } \\
\text { - } \text { supranuclear opthalmoplegia } \\
- \text { stiff facial features - lack of expression }\end{array}$ \\
\hline $\begin{array}{l}\text { Speech and } \\
\text { language features }\end{array}$ & 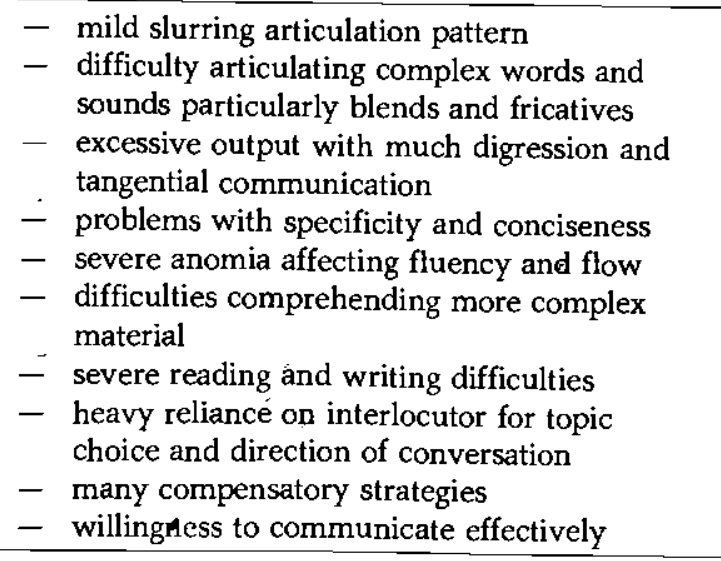 & $\begin{array}{l}\text { - pseudobulbar palsy } \\
-\quad \text { severe mixed dysarthria - speech highly } \\
\text { unintelligible } \\
- \text { apathy of spontaneous output } \\
-\quad \text { telegrammatic output with perseveration of } \\
\text { words and phrases } \\
- \text { reduced speed of word retriéval } \\
- \text { receptive language primarily intact. } \\
- \text { severe dysgraphia } \\
- \text { little self-initiated output } \\
- \text { heavy reliance on interlocutor } \\
-\quad \text { lack of compensatory strategies } \\
- \text { no apparent willingness to communicate } \\
\text { effectively. }\end{array}$ \\
\hline
\end{tabular}




\section{Assessment}

In addition to the standard battery of language and neuro. psychological tests, an analysis of both patients within a conversational framework was undertaken. The results on standard measures are summarized in table II and will not be described in detail here.

The focus of this paper will be on communicative testing. The method of analysis was the PCA originally devised by Penn (1985) to characterize the communicative performance of adult aphasics and is described in detail elsewhere (Penn, 1988). The 6 communicative components identified by the PCA are as follows:

A Response to interlocutor

B Control of semantic content

C Cohesion

D Fluency

E Sociolinguistic sensitivity

F Nonverbal communication

Penn [1988\} found that aphasic patients could be differentiated with regard to the relative retention of each of these components and such a profile is useful in characterizing communicative impairments of other neurological populations, eg. CHI (Irvine \& Behrmann 1986) and right hemisphere patients (Friedman 1986). guistic message in scales A (response to interlocutor); B (control of semantic content); $C$ (cohesion) seem more sensitive to instrumental functions such $\overline{a s}$ language and memory.

The communication of both patients was examined in an interactive framework with familiar conversational partners, the topic of conversation being on everyday events. Global ratings on a 5-point rating scale of appropriateness were made by two trained graduate language pathologists in terms of each of the categories using 15 minute videotaped samples. Results are presented in figure 1 and profiles appear in appendices $\mathrm{A}$ and $\mathrm{B}$.

\section{RESIIT.TS}

It was clear that there were marked differences on the PCA with respect to the profile and communicative characteristics between Patients A and B. On the whole, Patient A was construed to be more pragmatically appropriate in that, despite linguistic problems such as word finding difficulties and comprehension defects, she seemed an easy communicative partner, aware and compensating with excellent strategies for communicative interchange. On the other hand, Patient B seemed an unwilling an unmotivated partner whose interactions were largely elicited and restricted, with poor conversational flow. Detailed communicative profiles of each patient will now follow.

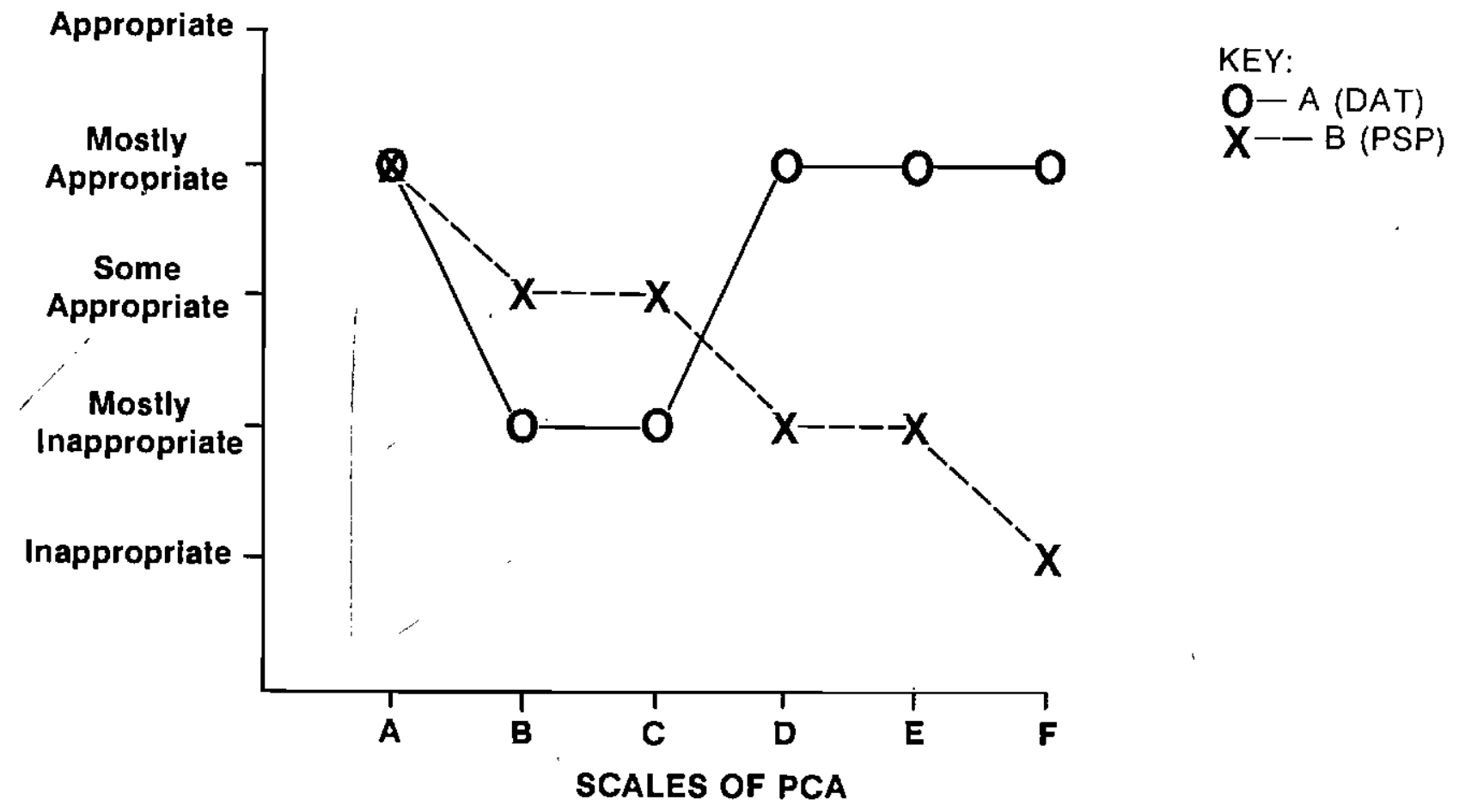

Figure 1:

Relative position of the subjects on a 5-point rating scale of appropriateness in relation to each scale of the PCA.

Returning to the instrumental-fundamental distinction proposed by Cummings (1986), it would appear that this scale may be sensitive to both these functions in that global aspects such as sociolinguistic sensitivity, non-verbal communication and overall fluency seem more closely linked to fundamental functions, while specific features of the lin-
Patient $A(D A T)$

Patient A's response to the interlocutor was felt to be mostly appropriate. She showed a willingness to respond to input and while often reliant on the interlocutor for the initiation of the topic, was able to proceed in the conversation. On oc- 
casion, her specific comprehension defect accounted for in. appropriate responses but self correction took place. Scale B (Control of semantic content), was frequently judged inappropriate. Topic initiation and shift and completion of ideas was often judged inappropriate. A number of incomplete phrases appearing in her transcript related strongly to her word fining difficulties resulting in a lack of accuracy and specificity, eg. "What's his name? He's got all the hotels. I know so well ... He goes around with the blonde girl." Such problems reflect also in scale $\mathrm{C}$ (Cohesion), where little sentence embedding was observed. However, linking devices, eg. pronouns were present. No agrammatism was observed.

Patient A's fluency behaviours were judged to be mostly appropriate and seemed linked to the word-finding difficulties which manifested in filled pauses and incomplete phrases.

Sociolinguistic sensitivity was judged to be mostly appropriate. She proved to be an extremely entertaining interlocutor with evidence of humour, reference to her conversational partner and self correction. She demonstrated good control of direct speech as well as a number of comment clauses, eg. "I know the name so well. Now you see, it shouldn't have gone out of my mind."

Non-verbal communication strategies such as gesture were used to support verbal behaviour and in fact served as a compensation yielding additional information. She had animated facial expression; used gesture and tone of voice. Occasional slowing of rate was noticed - possibly related to the mild dysarthria which manifested particularly in the production of blends.

\section{Patient B (PSP)}

On scale A \{response to interlocutor), Patient B also performed at a level of mostly appropriate. It should be noticed, however, that she was heavily reliant on the interlocutor for topic initiation and maintenance and her responses were restricted to short replies for, èg.

T: Did he send in his dig team?

P: I don't know. Yes.

T: Jean and Robbie were the main diggers.

P: Yes.

T: Did Rev go with you?

P: No.

This aspect was reflected particularly ín scale B (control of semantic content) where topics such as topic initiation and shift were judged inappropriate. In contrast, however, to Patient A, lexical choice and idea completion were appropriate.

Little opportunity to judge cohesion (scale $\mathrm{C}$ ) was available due to lack of spontaneity. However, l it seemed to be relatively unimpaired in that there was appropriate use of aspects such as tense and ellipsis. A number of nonfluencies were present in her conversational speech and were judged on occasion to interfere with communicative flow. In particular, pauses were felt to be lengthy, possibly related to the dysarthric element. Very few examples of aspects linked to social sensitivity were evident. Not observed were polite forms, reference to interlocutor, place holders, comment clauses, humour and control of direct speech. Generally the patient showed a general lack of interest and motivation in conversation, linking closely to the picture of adynamia described by Luria (Botez, Lucours \& Bérubé 1983). Non-verbal communication was extremely impaired and judged consistently inappropriate, particularly vocal aspects relating to intensity, pitch, rate, intonation and quality. These are a direct reflection of her severe mixed dysarthria. Non-verbal aspects were also related to the physical components of the disease, for example difficulties in lateral gaze.

\section{DISCUSSION}

The results indicated that both patients, with dementia of different etiologies, show a range of linguistic and communicative deficits. The pragmatic sequelae of the different disease processes and their outcomes leg. dysarthria in $\mathrm{Pa}$ tient $B$ ) are different and allow one to hypothesize as to the relationship between fundamental and instrumental processes on the one hand and components of pragmatics on the other. Despite specific linguistic deficits, Patient A was more communicatively appropriate than Patient $B$ and the severity of deficits appears more marked for B than A. This appears to be related primarily to a disruption of the fundamental aspects of motivation, mood, timing and arousal. Hence, while Patient A is motivated and alert in the communicative situation and focuses on maximizing communication flow and compensating for her deficits, Patient B has a basic deficit at the level of arousal which in turn influences more instrumental (linguistic) components of the interaction.

Albert et al. (1974) have hypothesized that the basic disorder in subcortical cases is one of arousal, timing and activation and this seems to be the essential feature differentiating it from the cortical pattern in Patient A.

The results of this study suggest that the area of language use is a complex and multidimensional one involving the operations of many different systems.

Figure 2 represents schematically the hypothesized relationship between fundamental and instrumental processes and their possible pragmatic counterparts.

In the area of topic control, for example, certain elements may be viewed as reflecting competence on a fundamental level while other aspects seem to be linked to an instrumental level. Topic initiation and shift seem more closely linked to fundamental processes in that arousal and initiative are prerequisites for such skills. Lexical specificity and sequencing seem more closely associated with instrumental processes, because they depend on linguistic competence.

At the level of communication therefore it appears that the cortical-subcortical differentiation seems to hold some validity. Whereas results from other research leg. Bayles and Tomoeda 1983) suggest that the cortical patient is more impaired in certain pragmatic tasks leg. judgment of a literal sentence) than some subcortical dementias such as Parkinson's and Huntington's cases, the present study confirms the suggestion that PSP is a type of subcortical dementia with a consistent intellectual deficit and which gravely affects the pragmatic level of language. The relatively widespread nature of the lesion in contrast to other subcortical 


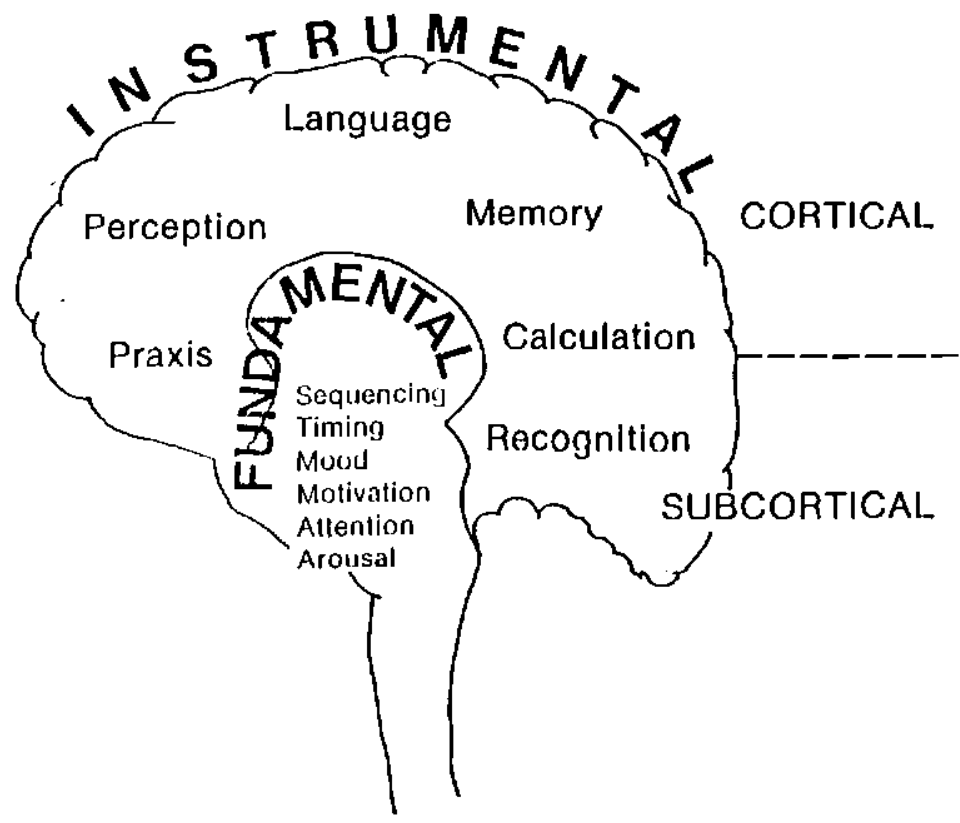

\title{
Hypothetical Pragmatic Counterparts
}

Comprehension; control of semantic content; topic maintenance; lexical choice and specificity; grammatical cohesion; fluency; gesture; sociolinguistic sensitivity; self-correction behaviours

Topic initiation, maintenance and shift; voc,al and non-verbal aspects (facial expression, eye contact and posture); awareness and response to interlocutor, rate, flow, coherence, contingency

\author{
Figure 2: \\ Schematic view of the brain showing-basic localization of processes \\ relevant to communication and their hypothesized pragmatic counterparts.
}

dementias seems to provide an explanation for this $[\mathrm{Cum}$ mings 1986). A clear connection to frontal lobe symptomatology is seen in this case as in all documented cases of PSP which has important implications for the language pathologist in terms of differential diagnosis.

Many of Patient B's symptoms and neurologic manifestations seem similar to traditional descriptions of dynamic aphasia as described by Luria and Tsvetkova (1970). They viewed the fundamental disturbance in dynamic aphasia as one affecting inner language and the predicative function. The initial idea of the action is present but the patient is unable to programme the action. The patient remains lacking in spontaneity and there is a major, usually global, decrease in physical and intellectual activity. Authors such as Botez et al. (1983) suggest that these symptoms are similar to those resulting from a lesion of the convexity of the frontal lobe. Such patients demonstrate a lack of initiative and drive. It is clear that the differences between dynamic aphasia and subcortical problems are not easy to observe and, given the rich anatomical connections (through the reticular activating system/ between the frontal lobe and the subcortical areas (Albert, 1978) it is possible that in some patients traditionally labelled as "dynamic aphasia" particularly in the presence of dysarthria and motor signs, the lesion may be more subcoritcal. The writers are in agreement with Cummings (1986) who suggests, that terms such as "frontalsubcortical systems disorder" might more accurately reflect the realm of anatomic, metabolic and neurochemical dysfunction found in this group of conditions.

Aside from the role in differential diagnosis, the language pathologist plays a critical role in the management of cortical and subcortical dementias (Bayles, 1986). Despite very poor ultimate prognosis, the role of the environment in dementia is felt to be particularly important. Both subjects in the present study were in a most supportive and understanding environment which in Patient A's case llike that of the patient with Pick's disease described by Holland,
McBurney \& Reinmuth 1985) would seem to contribute to the surprisingly spared pragmatic skills despite severe semantic and intellectual deterioration. Patient B, however, because of the severe physical concomitants of the disease and its effects on the fundamental processes, seemed unresponsive to environmental manipulation and therapy.

The role of the speech and language pathologist is that of information and support and from a communication framework, facilitating, maximising and adapting compensation behaviour both in the patient and in the family (Bayles 1986).

Clearly the type and intervention is determined by etiology and stage of dementia and will differ if fundamental as well as instrumental processes are involved. For example, $\mathrm{Pa}$ tient A responded well to a compensatory strategy paradigm which encouraged maximizing communicative performance. Patient B, however, was unresponsive to such efforts and environmental intervention was seen to be the most appropriate strategy.

The fundamental-instrumental dichotomy might perhaps have useful application to the treatment of other communicative disorders.

As with other neurogenic language disorders, the pattern of impairment in different diagnostic groups of dementia provides important implications for language organization in the brain.

Unlike other levels of language, eg. phonology, syntax and semantics, pragmatics seems to have much more generalized representation and depends on both cortical and subcortical integrity: "Pragmatic processing, like semantic, depends on conscious processing and results from the operation of other mental systems, among them perception, attention and abstraction" (Bayles, 1985). 
The results of this study suggest that one needs to analyze the components of such language use in an attempt to explain the symptoms. It is clearly not enough to say that a language problem exists in dementia, but we need to describe how that pattern manifests and what its implications are for overall communicative functioning. The results of this study confirm that "communicative impairment is an integral feature of the dementia syndrome" (Bayles, 1986) and that a pragmatic analysis may be useful in differentiating dementias of differing etiologies.

\section{REFERENCES}

Albert, M.L., Feldman, R.G. and Willis, A.L. The "Subcortical Dementia" of Progressive Supranuclear Palsy, Journal of Neurology, Neurosurgery and Psychiatry, 37, 121-130, 1974.

Albert, M.L. Subcortical Dementia. In: R. Katzman, R.D. Terry \& K.L. Bick (Eds.) Aging: Vol. 7. Alzheimer's Disease, Senile Dementia and Related Disorders. New York: Ravan Press, 1978.

American Psychiatric Association. Diagnostic and Statistical Manual of Mental Disorders (3rd Ed.) Washington, D.C., 1980.

Appell, J., Kertesz, A. and Fisman, M. A Study of language functioning in Alzheimer patients. Brain and Language, 17, $73-91,1982$.

Bayles, K.A. Language and Dementia. In: A.L. Holland (Ed.) Language Disorders in Adults. San Diego: College-Hill Press, 1984.

Bayles, K.A. Communication in dementia. In: H.K. Ulatowska [Ed.] The Aging Brain: Communication in the Elderly. San Diego: College-Hill Press, 1985.

Bayles, K.A. Management of communication disorders associated with Dementia. In: Language Intervention Strategies in Adult Aphasia. R. Chapey (Ed.) Williams \& Williams: New York, 1986.

Bayles, K.A. and Kaszniak, A.W. Communication and Cognition in Normal Aging and Dementia. London: Taylor and Francis Limited, 1987.

Bayles, K.A. and Tomoeda, C.K. Confrontation naming impairment in dementia. Brain and Language, 19, 98-114, 1983.

Botez, M.I., Lecours, A.R. and Bérubé, L. Speech and language in the frontal syndrome. In: Aphasiology, A.R. Lecours, F. Lhermitte and B. Bryans (Eds.) London: Baillière Tindall, 1983.

Cummings, J.L. Subcortical dementia. Neuropsychology, neuropsychiatry and pathophysiology. British Journal of Psychiatry, $149,682-697,1986$.

Cummings, J.L. and Benson, D.F. Subcortical dementia. Review of an Emerging Concept. Archives of Neurology, 41, 874-879, 1984.

Cummings, J.L. and Benson, D.F. Dementia of the Alzheimer type. J. of the American Geriatrics Society, 34, 12-19, 1986.

D'Antona, R., Baron, J.C., Samson, Y., Serdara, M., Vidder, F., Agid., Y. and Cambier, J. Subcortical Dementia. Frontal cortex hypometabolism detected by position tomography in patients with Progressive Supranuclear Palsy, Brain, 108, $785-799,1985$

Freedman, M. Cortical and subcortical dementia. Annals of Neurology, 15, 506-507, 1984.
Friedman, A. Language deficits in patients with right hemisphere lesions. Undergraduate research report, University of the Witwatersrand. 1986

Holland, A.L., McBurney, D.H. and Reinmuth, O.M. The dissolu tion of language in Pick's disease with neurofibrillary tangles: A case study. Brain and Language, 24, 36-58, 1985 .

Horner, J. and Royall, J.B. Longitudinal change in spoken language in dementia of Alzheimer type. Paper presented at ASHA Convention, Washington, 1985.

Huber, S.J. and Paulson, G.W. The concept of subcortical demen tia. American Journal of Psychiatry, 142, 1312-1317, 1985.

Huber, S.J., Shuttleworth, E.C., Paulson, G.W., Bellchambers, M.J.G. and Clapp, L.E. Cortical vs subcortical dementia, neuropsychological differences. Archives of Neurology, 43 392-394, 1986.

Irvine, $\mathrm{L}$. and Behrmann, $\mathrm{M}$. The communicative and cognitive deficits following closed head injury. South African Journal of Communication Disorders, 33, 49-54, 1986.

Izzo, K.L., Dilotenzo, P. and Roth, A. Rehabilitation in PSP: Case Report Arch. Phys. Med. Rehabil. 67, 473-476, 1986.

Jonati, A and Appell, A.R. Psychiatric aspects of Progressive Supranuclear Palsy. Journal of Nervous and Mental Disorders. $172,85-89,1984$.

Kristensen, M.O. Progressive Supranuclear Palsy -20 years later. Acta. Neurol. Scand., 71, 177-189, 1985

Luria, A.R. and Tsvetkova, L.S. The mechanism of 'dynamic aphasia'. In: Progress in Linguistics. M. Byerwish and K.E. Heidolph (Eds.) Mouton: The Hague, 1970.

Maher, E.R. and Lees, A.J. The clinical features and natural history of the Steele-Richardson-Olszewski Syndrome [PSP). Neurology, 36, 1005-1008, 1986.

Maher, E.R., Smith, E.M. and Lees; A.J. Cognitive deficits in the Steele-Richardson-Olszewski Syndrome (Progressive Supranuclear Palsy). Journal of Neurology, Neurosurgery and Psychiatry, 48, 1234-1239, 1985.

Mayeux, R., Stern, Y., Rosen, J. and Benson, D.F. Is "subcortical dementia" a recognizable clinical entity? Annals of Neurology, 14, 78-283, 1983

Obler L.K. and Albert, M.L. Language in the elderly aphasic and in the dementing patient. In: M.T. Sarno [Ed.] Acquired Aphasia. New York: Academic Press, 1981

Penn, C. The Profile of Communicative Appropriateness. South African Journal of Communication Disorders, 32, 18-32, 1985

Penn, C. The profiling of syntax and pragmatics in aphasia. Clinical Linguistics and Phonetics, 2 |3|, 179-207, 1988.

Pillon, B. Dubois, B. Lhermitte, F. \& Agid, Y. Heterogeneity of cognitive impairment in Progressive Supranuclear Palsy, Parkinson's Disease and Alzheimer's Disease. Neurology, 36 1179-1185, 1986

Ruberg, M., Javoy-Agid, F., Hirsch, E., Scatton, B. Lheureux, R. Hauw, J.J., Duyckaerts, C., Gray, F. Morel-Maroger, A: Rascol, A., Serdara, M. and Agid, Y. Dopaminergic and cholinergic lesions in Progressive Supranuclear Palsy. An. nals of Newrology, 18, 523-529, 1985.

Schneck, M.K. Reisberg, B. and Ferris, S.H. An overview of current concepts of Alzheimer's Disease. American Journal of Psychiatry, 139, 1982.

Steele, J.C. Progressive Supranuclear Palsy. Brain, 95, 693-704 1972. 
APPENDIX A

Profile of conmunicative appropriateness

Name_PATIENT A

Features of sampling

Date

Unit of analysis

A

Person eliciting sampie

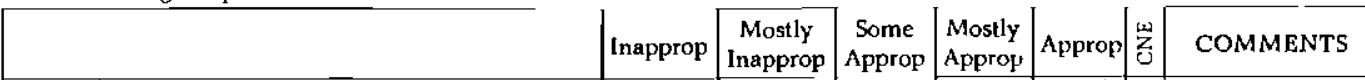

C

\begin{tabular}{l|l} 
Request \\
Reply
\end{tabular}

总总

Clarification request

Teaching probe

Others

Topic initiation

Topic adherence

岁苞 Topic shift

苍苛 Lexical choice

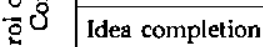

: Idea sequencing

Others

Ellipsis

Tense use

Reference

.

\& Relative clauses

Prenominal adjectives

Conjunctions

Others

Interjections

Repetitions

Revisions

D

总

Incomplete phrases

Pauses

Word-finding difficulties

Others!

Polite forms

Reference to interlocutor

Placehólders, fillers, stereotypes

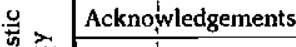

Self correction

Comment clauses

Sarcasin/humour

Control of direct speech

Indirect speech acts

Others

Vocal aspects: Intensity

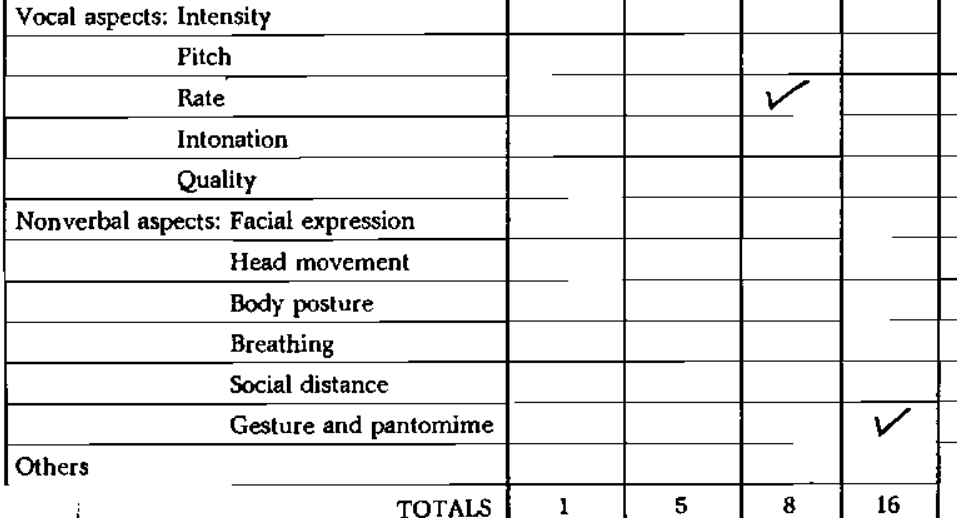

TOTALS

16

13.2 
APPENDIX B

Profile of communicative appropriateness

Name PATIENT B

Features of sampling

Date

Unit of analysis

Person eliciting sample

A

\begin{tabular}{|c|c|c|c|c|c|c|c|c|}
\hline & & Inannon & Mostly & Some & Mostly & Annes & 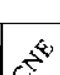 & COMMFNTS \\
\hline \multirow{6}{*}{ 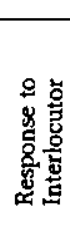 } & Panuant & & & & eppro & & & \\
\hline & \begin{tabular}{|l} 
Keque \\
Penls
\end{tabular} & & & & $\checkmark$ & & & \\
\hline & \begin{tabular}{|l} 
Reply \\
Clarification request
\end{tabular} & & & & & & 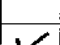 & \\
\hline & $\begin{array}{l}\text { Clanincation reques } \\
\text { Acknodgeme }\end{array}$ & & & 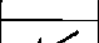 & & & & \\
\hline & Acchoweagem & 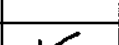 & & & & & & \\
\hline & 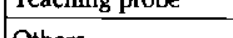 & & & & & & & \\
\hline
\end{tabular}

B

Topic initiation

Topic adherence

曾 Topic shift

岁 Lexical choice

워 Idea completion

8

Idea sequencing

Others

Eltipsis

Tense use

Reference

C

모 Lexical substitution forms

용 Relative clauses

Prenominal adjectives

Conjunctions

Others

Interjections

Repetitions

Revisions

总

Incomplete phrases

False starts

Pauses

Word-finding difficulties

Others

Polite torms

Reference to interlocutor

Placeholders, fillers, stereotypes

E

苟

Acknowledgements

Self correction

Comment clauses

Sarcasm/humour

Control of direct speech

Indirect speech acts

Others

Vocal aspects: Intensity

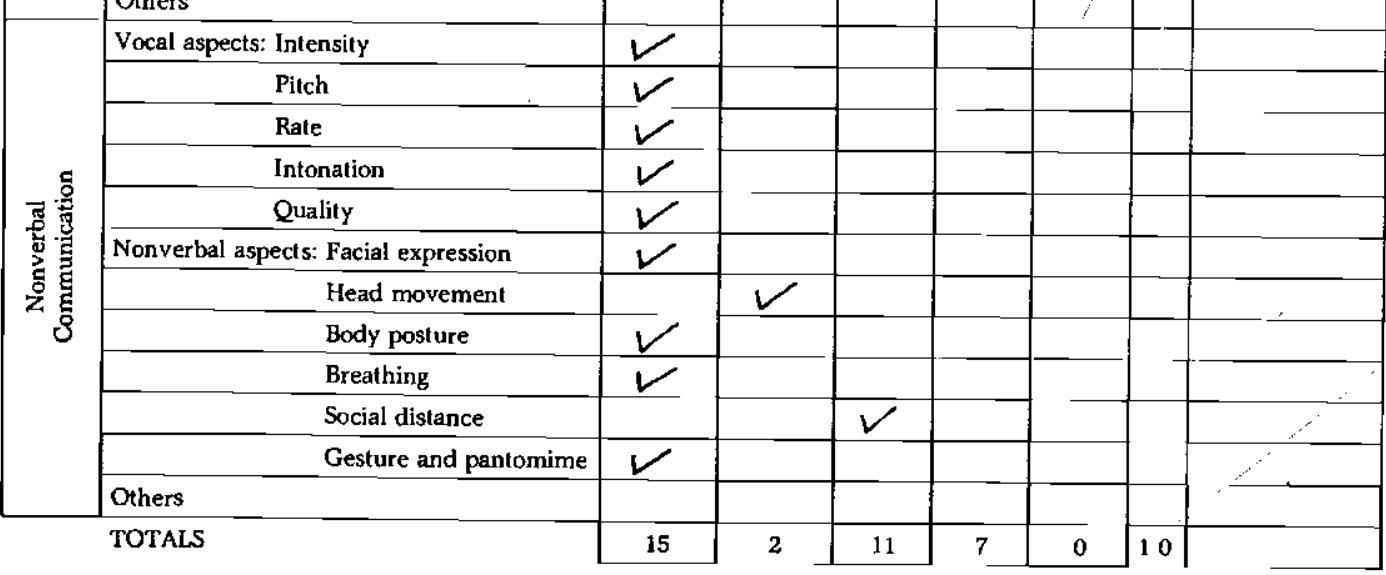

